\title{
Development of the Retinotectal Projection in Zebrafish Embryos under TTX-Induced Neural-Impulse Blockade
}

\author{
Claudia A. O. Stuermer, ${ }^{1}$ Bärbel Rohrer, ${ }^{1}$ and Heinrich Münz ${ }^{2}$ \\ 'Friedrich-Miescher-Laboratorium der Max-Planck-Gesellschaft, Tübingen, Federal Republic of Germany and ${ }^{2}$ Faculty of \\ Biology, University of Bielefeld, Bielefeld, Federal Republic of Germany
}

\begin{abstract}
The influence of neural activity on the morphology of retinalaxon-terminal arbors and the precision of the developing retinotectal projection in zebrafish embryos was explored. Terminal-arbor morphology and their distribution in the tectum was determined with anatomical fiber-tracing methods using the fluorescent dyes dil and diO. To allow development under activity-deprived conditions, TTX was injected into the eyes of 30-38-hr-old zebrafish embryos at concentrations that effectively blocked neural activity both in retinal ganglion cells and throughout the CNS.
\end{abstract}

Much like axons with normal neural-activity patterns, activity-deprived axons from dorsal and ventral and from temporal and nasal regions in the retina terminated over retinotopically appropriate and nonoverlapping regions of the tectum. Even after ablation of 1 hemiretina at the time of axonal outgrowth, activity-deprived axons from the remaining hemiretina grew directed toward and arborized selectively within their retinotopically appropriate tectal half in the same way as would nondeprived axons.

Besides being retinotopic, the area over which small populations of activity-deprived axons from neighboring ganglion cells arborize is as small as that of active axons. The size of terminal arbors of retinal ganglion cell axons was unaffected by blockade of neural activity. The mean terminal-arbor size was $27 \times 18 \mu \mathrm{m}$ for the TTX-injected and 31 $\times 22 \mu \mathrm{m}$ for the control embryos. The tectal coverage of TTX-blocked and control axons was equally small, with values of $1.4 \%$ and $1.6 \%$, respectively. These data show that a precisely organized retinotopic map in developing zebrafish forms independent of neural-impulse activity.

The high degree of retinal-axon-terminal order in the vertebrate visual system has led to an extended search for the cellular mechanisms underlying the precision of its development. Two classes of mechanisms are currently being considered that could account for the establishment of a precisely ordered projection: axonal guidance by positional markers and activity-mediated axon-target interactions. A widely held view is that a crude retinotopic order is established without neural activity, but that

Received Jan. 23, 1990; revised June 25, 1990; accepted June 28, 1990.

We wish to thank Anette Habring-Müller for her excellent technical assistance and Roswitha Groemke-Lutz for the photographic reproductions. Dr. Tom Abrams read and corrected the manuscript.

Correspondence should be addressed to C. A. O. Stuermer, Friedrich-MiescherLaboratorium der Max-Planck-Gesellschaft, Spemannstrasse 37-39, D-7400 Tübingen, FRG. After January 1, 1991: C. A. O. Stuermer, Faculty of Biology, University of Konstanz, D-7750 Konstanz, FRG.

Copyright (C) 1990 Society for Neuroscience $0270-6474 / 90 / 113615-12 \$ 03.00 / 0$ precise topographic terminations require activity (for review, see Purves and Lichtman, 1985; Udin and Fawcett, 1988). Studies to define the degree to which neural activity is required have generally employed the sodium-channel blocker TTX (e.g., Harris, 1980; Schmidt and Edwards, 1983; Stryker and Harris, 1986).

The degree to which activity improves a projection, or, conversely, the degree to which activity deprivation causes a degradation, of retinal-axon-terminal order may vary among species (see Discussion). Quite striking is the effect that TTX-induced impulse blockade has on the retinogeniculate axons in kittens. The initially large axon arbors fail to shrink to their eye-specific layer of the LGN. Moreover, they also become considerably larger in their lateral extent, which clearly deteriorates the retinotopic order normally found in this system (Sretavan et al., 1988). Increase in arbor size is also reported to be a consequence of TTX-induced activity deprivation in frogs (Reh and Constantine-Paton, 1985).

In the regenerating goldfish retinotectal system, retinal axons arborize widely (Schmidt et al., 1988a; Stuermer, 1988a,b) like embryonic axons in the kitten (Sretavan et al., 1988). In contrast to the kitten, in fish the formation of small arbors at retinotopic sites and the retraction of side branches from ectopic regions appear to take place independently of activity (Hartlieb and Stuermer, 1989). However, decline of the multiunit receptivefield sizes (MURFs) from large to normal size, determined electrophysiologically in fish after regeneration, appears to require neural activity at least to proceed at the normal rate (Schmidt and Edwards, 1983).

In contrast to the normal retinogeniculate development in the kitten and the regeneration of retinal axons in the goldfish, arbors in the developing retinotectal projection in zebrafish embryos are small, and a high degree of retinotopic order exists from the very beginning (Stuermer, 1988c). This raised the question of whether this early retinotopic order in zebrafish embryos required neural activity. We have asked whether activity blockade by TTX would lcad to an enlargement of axon arbors and to a degradation of the retinotopic precision. This study employed anatomical techniques using crystals of 1,1'-dioctadecyl3,3,3', $3^{\prime}$-tetramethylindocarbocyanine (diI) and 3, $3^{\prime}$-dioctadecyloxacarbocyanine (diO) to label axons from small groups of ganglion cells (Stuermer, 1988c). Together with the evidence that developing retinal axons arborize over small and retinotopicully appropriate tectal regions, measurements both of the relative tectal area occupied by terminal arbors from neighboring ganglion cells and of the sizes of individual terminal arbors and their tectal coverage show that neural-impulse blockade does not perturb the precision of the retinal-axon-terminal order in the developing retinotectal system of zebrafish embryos. 


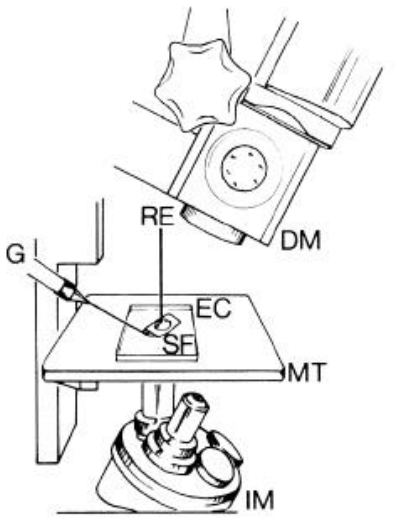

Figure 1. Experimental setup for electrophysiological recordings from zebrafish embryos. See Materials and Methods for details. $D M$, dissection microscope; $I M$, inverted microscope; $M T$, stage; $G$, ground electrode; $R E$, recording electrode; $S F$, aluminium foil; $E C$, experimental chamber.

Part of these results were published in abstract form (Stuermer, 1988d).

\section{Materials and Methods}

Embryos of the zebrafish, Brachydanio rerio, were obtained from a laboratory colony and raised at $28^{\circ} \mathrm{C}$. Eggs were collected and staged within 1-2 hr after spontaneous spawning. Zebrafish hatch between 48$72 \mathrm{hr}$ and reach adulthood by 3-4 months. For experimental manipulations of embryos prior to hatching, embryos were freed from their egg cases with pointed needles. Embryos were placed on moist tissue and anesthetized with $0.007 \%$ tricaine methane sulphonate (MS222; Sigma). Embryos between 30 and $38 \mathrm{hr}$ postfertilization (PF) received injections of 8-10 nl 0.12 mм TTX (Sigma) in Ringer's solution in 1 eye, delivered with a calibrated pointed glass needle by pressure. Following these injections, most embryos were entirely paralyzed, except for their heartbeat. Therefore, in contrast to adult fish, in which intraocularly injected TTX remains confined to the eye (Schmidt and Edwards, 1983; Hartlieb and Stuermer, 1989), it most likely diffuses in embryos through the entire body. At the time of injection, the embryos were about $2.6 \mathrm{~mm}$ long, and their eyes had a diameter of $130 \mu \mathrm{m}$. The entire volume of the embryo, including its yolk sac, was calculated to be around $200 \mu \mathrm{l}$. Under the assumption that the injected TTX becomes distributed uniformly throughout the embryo, the TTX concentration in the embryo should be around $5 \times 10^{-9} \mathrm{M}$. By the time the embryos were subjected to further experimental manipulations (dye application, lesions, or fixation), some (between 0 and $30 \%$ ) had recovered motility and twitched upon touch or (rarely) spontaneously. These embryos were not included in the analyses. One group of control embryos was treated similarly but received injections of pure Ringer's solution instead of TTX. Paralyzed embryos and control embryos were kept in separate Petri dishes at $28^{\circ} \mathrm{C}$ until and after the application of the dyes diI and diO (see below). Another group of embryos remained in their egg cases until dye applications were performed in order to judge whether the removal from the egg cases and/or the injections would delay the embryos' normal development.

Electrophysiological recordings. To monitor light-evoked potentials in the tectum and the effects of TTX injections on the electrical activity, electrophysiological recordings were performed on 2 groups of TTXinjected animals and controls. In the first group, 10 embryos at $72 \mathrm{hr}$ PF were injected with Ringer's solution, and 5 with TTX solution, and recordings were taken from these embryos between 72 and $86 \mathrm{hr}$ PF. In the second group, embryos were injected with Ringer's or TTX solution between 30 and $38 \mathrm{hr}$ PF (as for our anatomical studies), and recordings were taken from embryos of the following ages: TTX-injected embryos: 79, 102, 104, 127, 145, 151, 155, and $156 \mathrm{hr}$ PF; Ringerinjected embryos: $79,101,124,129,132$, and $148 \mathrm{hr}$ PF.

Ringer-injected embryos were immobilized in $0.007 \%$ Alloferin (Roche) prior to recordings. Fish were transferred to a drop of $20 \%$ gelatine, held by a ring of aluminium foil, and placed in a small glass

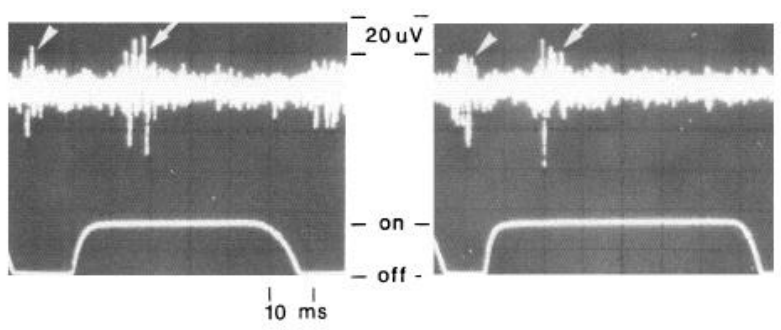

Figure 2. Display of 2 typical multiunit recordings from tectum in 84 hr-PF Ringer-injected embryo after visual stimulation of eyes with light "off" (arrowheads) and "on" (arrows).

chamber (Fig. 1). The chamber was filled with Ringer's solution, and the temperature was kept at $20^{\circ} \mathrm{C}$ by a Peltier cooling device. Embryos were viewed from below using an inverted microscope (Fig. 1), which allowed control of the positioning of the electrode as well as visual monitoring of the fish's heartbeat and capillary blood flow. The experimental chamber was also viewed from above with a dissecting microscope.

Heartbeat and capillary blood flow were normal in all fish throughout these treatments, as well as during and after the recording session. The investigator performing the recordings (H.M.) was not informed whether a particular fish had been injected with TTX or Ringer's solution.

Recording and visual stimulation. Multiunit activity was recorded in the midbrain using alloy-filled glass microelectrodes (Dowben and Rose, 1953). Electrode-tip diameters were in the range of 2 to $10 \mu \mathrm{m}$. Potentials were amplified with a WPI Dam 80 preamplifier $(1000 \times, 1-3000-\mathrm{Hz}$ bandpass) monitored by an oscilloscope and stored on tape for further processing.

The electrode was advanced directly through the skin covering the tectum using a hydraulic microdrive. The skin of the animals is translucent, which allowed positioning of the electrode under visual control through the 2 microscopes (accuracy of the electrode position, about 50 $\mu \mathrm{m})$.

The eyes were stimulated with optic bright-field stimuli. Maximal light intensity used was about 3000 lux. The time course of the light stimulus was monitored by the potential of a silicon photocell.

In all 16 animals of groups 1 and 2 that were injected with Ringer's solution, visually induced neuronal activity was found in the tectum. The units showed no baseline activity and reacted to visual stimuli with on-off or off-on responses (Fig. 2). An increase of the stimulus-repetition rate led to a reduction of the units' response rates. Recordings remained stable up to $1 \mathrm{hr}$ (maximum time tested). In 14 of 16 control animals, visual activity was recorded with the first electrode in the first penetration. In 2 animals between 70 and $84 \mathrm{hr} \mathrm{PF}$, a second electrode was needed to find visual activity in the tectum. Besides the visual units, background activity with a low signal-to-noise ratio was found in the midbrain of the control animals, indicating nonvisual tectal or subtectal neuronal activity. Among the TTX-treated embryos of group 2, the one at $155 \mathrm{hr}$ PF twitched upon touch, and the one at $156 \mathrm{hr}$ PF moved spontaneously. Although embryos with mobility were usually discarded, we chose these 2 for electrophysiological recordings from the tectum to decide whether recovery from paralysis correlated with the (re)appearance of visually evoked responses in the tectum. Recordings indeed showed light-evoked activity but not at every electrode position. Furthermore, spikes appeared smaller; however, we did not try to substantiate this observation by extended recording sessions.

In the other TTX-treated fish, the 5 of group 1 and the remaining 6 of group 2 (all of which were paralyzed) showed no neuronal activity either in the tectum or in subtectal regions. In animals of group 1, we tried to record activity with 3 electrodes along 10 tracks each, as well as with 1-4 electrodes in 4-10 tracks in those of group 2, and found no visual elicited or background activity in the midbrains of any of these fish. This means that TTX had effectively blocked neuronal activity in their CNS. All TTX-injected fish without midbrain activity were still alive, judged by their constant heartbeat rate and blood flow.

Applications of diI and diO. At $42-48 \mathrm{hr}$ PF, crystals of the fluorescent dyes diI (1,1'-dioctadecyl-3,3,3',3'-tetramethylindocarbocyanine; Molecular Probes) and diO (3,3'-dioctadecyloxacarbocyanine perchlorate; Serva) were inserted into 1 retina, as previously described (Stuermer, 1988c). DiI and diO were applied simultaneously to 2 different positions 
a
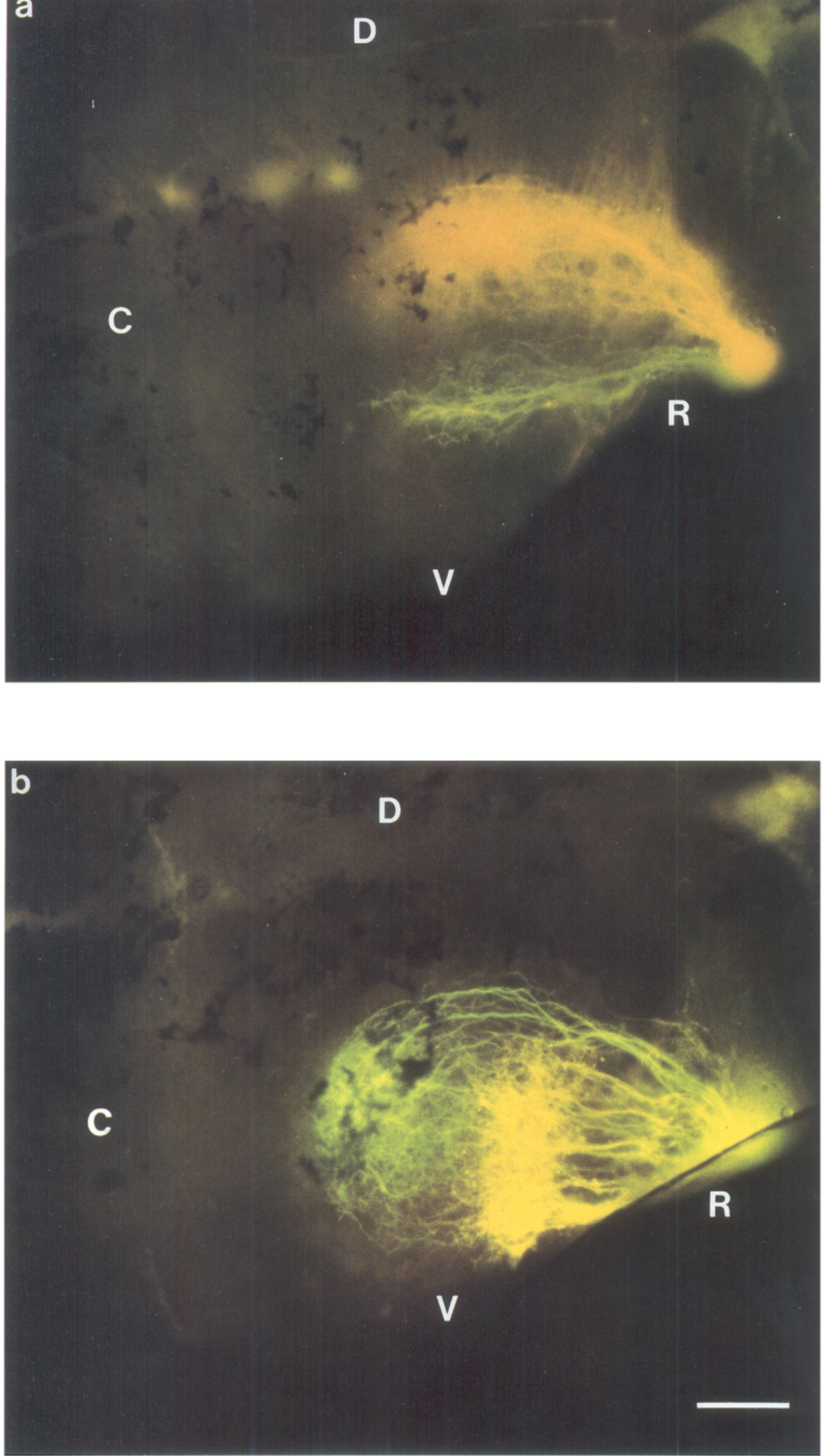

Figure 3. $a$, Dorsal view of right tectum of 83-hr-PF TTX-injected embryo. The diI-labeled (yellow) axons originating in the ventral retina travel through the dorsomedial brachium of the optic tract and arborize in the dorsal half of the tectum. The diO-labeled (green) axons enter through the ventrolateral brachium and arborize in the ventral hemitectum. This embryo, as well as those shown in Figure 4, had remained in PBS with the labeled eye in place for $1 \mathrm{hr}$ to increase the intensity of the label in the axons. Because this frequently leads to a passage of the dye from the axons to the neighboring cells, cells in the marginal growth zone of the tectum fluoresce lightly. $b$, Dorsal view of right tectum of 75-hr-PF TTX-injected embryo. The dil-labeled (yellow) axons from the temporal retina arborize exclusively over the rostral tectal half. The diO-labeled (green) axons from the nasal retina pass through the rostral tectum to terminate in their retinotopically appropriate caudal tectal half. Scale bar, $50 \mu \mathrm{m}$. $R$, rostral; $C$, caudal; $D$, dorsal; $V$, ventral. 
of the retina in the TTX group, and later the distribution of the labeled axons was compared to that of normal (i.e., uninjected) embryos of an earlier study (Stuermer, 1988c). To visualize individual terminal arbors and to determine their extents, small crystals of either diI or diO were inserted intraretinally in the TTX-injected, Ringer-injected, and uninjected groups. Dye applications in the TTX group were only performed in embryos that were still entirely paralyzed. Embryos that twitched upon touch (a normal reaction in all embryos that have not been exposed to TTX) prior to fixation were discarded. At defined stages, between 70 and $100 \mathrm{hr}$ PF (see Figs. 7-9), the embryos were fixed in 4\% paraformaldehyde in PBS (pH, 7.4) for a minimum of $30 \mathrm{~min}$.

In an earlier procedure (Stuermer, 1988c), embryos were dissected 15 min after fixation. Here, we left the embryos for $1-4 \mathrm{hr}$ in PBS before removing the eyes and the skin overlying the brain. This resulted in an intensification of the labeling of the axons in the tectum, probably resulting from diffusion of the dye (Godement et al., 1987), and caused less rapid fading during photography or viewing. This also led, in some instances, to a diffusion of diI from the axons into the neighboring tectal cells, as seen in Figure $3 a$. Still, intense labeling of axons was clearly distinguishable from the lighter staining of cells.

Partial retinal ablations. As described in an earlier study (Stuermer, $1988 \mathrm{c}$ ), either the nasal or temporal retina or the dorsal or ventral retina was ablated in 30-34-hr-PF embryos after they had received TTX or Ringer's solution injections. The surgery was repeated at $40-48 \mathrm{hr} \mathrm{PF}$, because the ablated retina appeared to be gradually restored (Stuermer, $1988 \mathrm{c})$. With the second lesion, small crystals of diI or diO were inserted into small portions of the remaining hemiretina. These embryos were fixed and analyzed at 72-84 hr PF.

Measurements of axonal arbors and tectal extent. Under illumination with UV light and fluoroscein isothiocyanate (FITC) and rhodamine isothiocyanate (RITC) filter sets, axon arbors and their branches, which were visible throughout their entire extent into their finest processes when viewed with $100 \times$ oil-immersion objective, were drawn with the aid of a drawing tube. The extent of the tectum and that of the tectal neuropil were drawn using a $20 \times$ lens. As described earlier (Stuermer, $1984,1988 \mathrm{c}$ ), a line connecting each of the tips of the branches and the first bifurcation point of the axon was drawn. This shape was approximated by an ellipse. The long and short axes of this elliptical area were measured, and the area was approximated by the formula to calculate the area of an ellipse. The area of the total tectal neuropil was measured in each embryo by similarly fitting an ellipse. Both areas were put into relation to calculate the tectal coverage of the arbors by dividing the arbor area by the tectal area, and the values were expressed as percentages.

\section{Results}

Under TTX-induced paralysis, most zebrafish embryos developed normally, and retinal axons had covered the tectal neuropil over its rostrocaudal extent by $70-72 \mathrm{hr}$ PF.

Whether activity deprivation by TTX during retinal axonal growth would affect the order of the axon terminal arbors in the tectum and the axon's morphology was assessed by determining the paths, termination pattern, and extent of individual terminal arbors and the tectal neuropil area in embryos between 70-100 hr PF. Embryos that had received injections of TTX at 30-36 hr PF were compared to embryos injected with Ringer's solution at the same age and to normal, uninjected embryos.

\section{Retinotopic termination of $T T X$-blocked retinal axons}

In normal embryos, axons terminate over retinotopically appropriate and well-defined domains in the tectum (Stuermer, $1988 \mathrm{c}$ ). To determine whether this precision of the retinotectal projection requires neural activity, the projections of TTX-treated animals were visualized by labeling axons with diI and diO at $40-50 \mathrm{hr}$ PF.

Figure $3 a$ illustrates the distribution of dil- and diO-labeled axons in a tectum of a TTX-injected and paralyzed embryo at $83 \mathrm{hr}$ PF. The diI crystal had been inserted in the dorsal, and the diO crystal into the ventral, retina at $48 \mathrm{hr} \mathrm{PF}$. As seen in Figure $3 a$, the dorsal diI-labeled (yellow) axons had grown through the retinotopically appropriate ventral brachium of the optic tract into the ventral hemitectum, where they arborized. The diO-labeled ventral (green) axons passed through their retinotopically appropriate dorsal brachium into the dorsal hemitectum, and their arbors were restricted to this hemitectum.

Figure $3 b$ shows the distribution of the nasal and temporal axons in a tectum at $75 \mathrm{hr}$ PF, labeled from insertions of dil and diO crystals into the retina at $50 \mathrm{hr}$ PF. DiI-labeled temporal axons (yellow) arborized exclusively over the rostral tectum. The diO-labeled nasal axons (green) crossed through the rostral tectal half to occupy their retinotopically appropriate caudal tectal half.

In all 72 tecta from the TTX-injected embryos between 72 and $96 \mathrm{hr} \mathrm{PF}$, retinal axons growing in the absence of neural activity terminated over their retinotopically correct target domains in the tectum in a manner indistinguishable from that of normal axons.

\section{Partial retinal ablations}

Retinal ganglion cells from eyes in which half of the retina had been removed grew along normal target-directed routes and had restricted axon terminals in the tectum (Stuermer, 1988c). We asked whether the axons in TTX-paralyzed fish missing half of the retina would behave similarly. The nasal or temporal and the ventral or dorsal hemiretina was surgically removed in 20 TTX-injected embryos at or prior to the time of axonal outgrowth from the eye. When analyzed at 77-84 hr PF, the paths and branching patterns of the diI-labeled axons from the remaining hemiretina were as directed and selective as were the paths of axons from hemiretinae in noninjected fish (Stuermer, $1988 \mathrm{c}$ ). Figure $4 h$ shows dil-labeled axons from a nasal hemiretina in a tectum of a TTX-injected embryo at $84 \mathrm{hr} \mathrm{PF}$, after ablation of the temporal retina at $34 \mathrm{hr}$ and $48 \mathrm{hr}$ PF. Figure $4 a$ shows temporal axons after removal of the nasal retina (at 34 and $48 \mathrm{hr}$ PF) in a TTX-injected embryo at $77 \mathrm{hr}$ PF.

The temporal axons remained restricted over the rostral tectal half and did not invade the uninnervated caudal tectum (Fig. 4a). Nasal axons in TTX-injected fish passed the "vacant" rostral tectum and arborized selectively in the caudal tectal half (Fig. $4 b$ ). The same precision of targeting was observed for the dorsal and ventral axons in the absence of their counterparts. Thus, in fish with TTX blockade of activity, the developing retinal axons grow to and terminate at their retinotopic sites and thus behave like axons in embryos that were not exposed to TTX (Stuermer, 1988c).

\section{Precision of targeting of TTX-blocked axons}

In 16 of the tecta of the experiment described first, the clusters were smaller than a tectal quadrant, indicating that axon targeting is better than quadrant-to-quadrant mapping. The finer order of a projection depends on both axon-arbor size and the reproduction of the neighborhood relationship of the ganglion cells on the level of their terminal arbors. If arbors are small (see below), the smallest clusters made up by a group of axons from neighboring ganglion cells can permit an estimate on the precision of projection by retinal axons (Stuermer and Raymond, 1989). Therefore, we measured the smallest clusters in tecta of TTX-injected embryos and compared them to those in normal (uninjected) embryos, part of which were derived from 

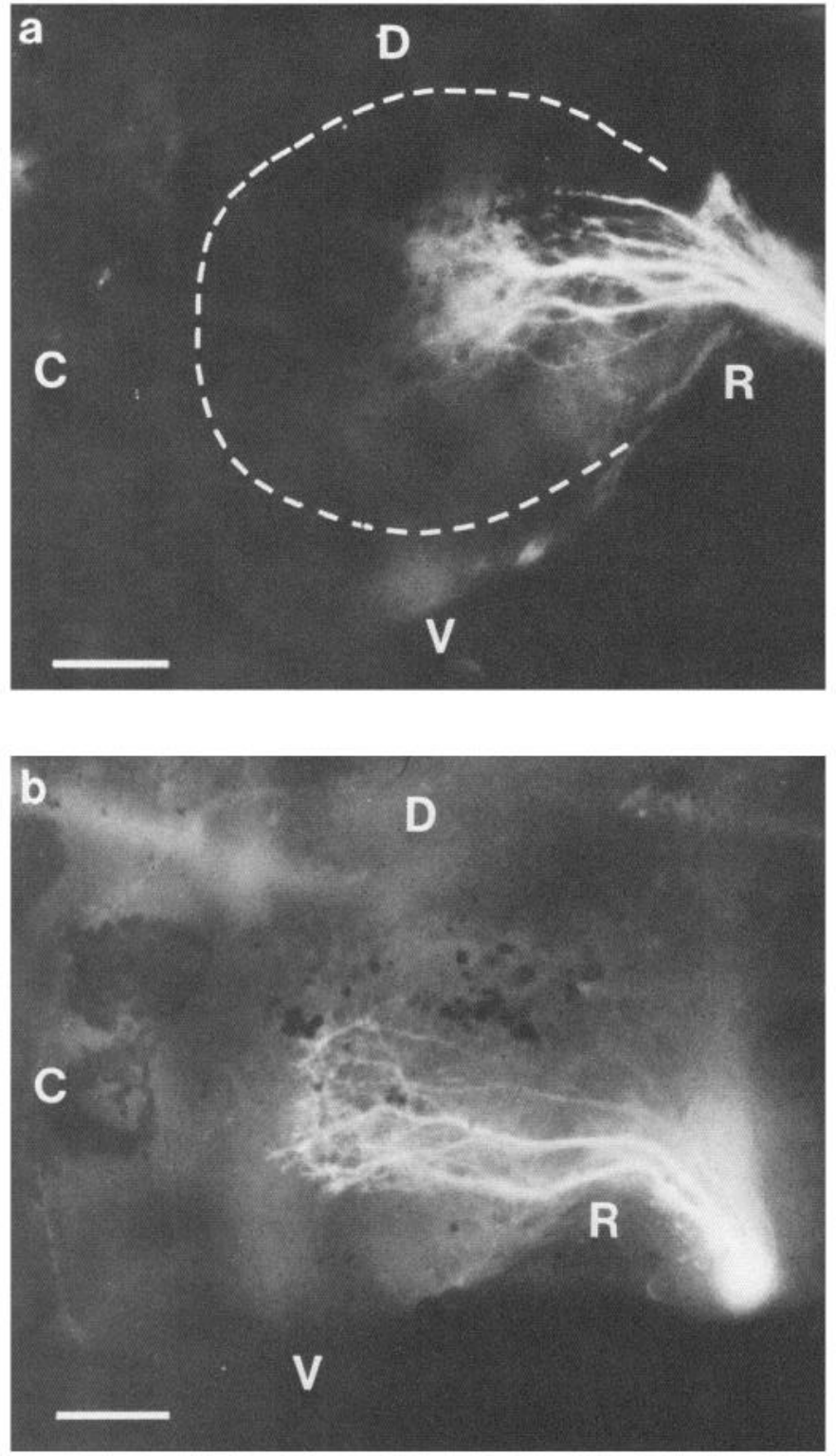

Figure 4. $a$, Dorsal view right tectum of 84-hr-PF TTX-injected embryo. Following the ablation of the nasal retina, the temporal activitydeprived axons, stained by an insertion of diI into the retina, terminate exclusively in the rostral tectal half. The boundary of the tectal neuropil is indicated by the broken line. $b$, Dorsal view of right tectum of $77-\mathrm{hr}-$ PF TTX-injected embryo. In the absence of the temporal axons, missing due to an ablation of the temporal retina, the nasal activity-deprived axons stained with diI pass over the vacant rostral tectum and arborize selectively in their retinotopically appropriate caudal tectal half. $D$, dorsal; $R$, rostral; $V$, ventral; $C$, caudal. Scale bar, $50 \mu \mathrm{m}$.

an earlier study (Stuermer, 1988c). These measurements were taken from selected tecta of the first experimental group described above and in additional embryos that had received applications of either diI or diO into their retinae (see below).

A general observation was that larger clusters consisted of a large number of axons, and smaller clusters consisted of considerably fewer axons. The clusters were always situated in retinotopically appropriate tectal regions.

Tecta exhibiting the smallest clusters of terminal arbors were
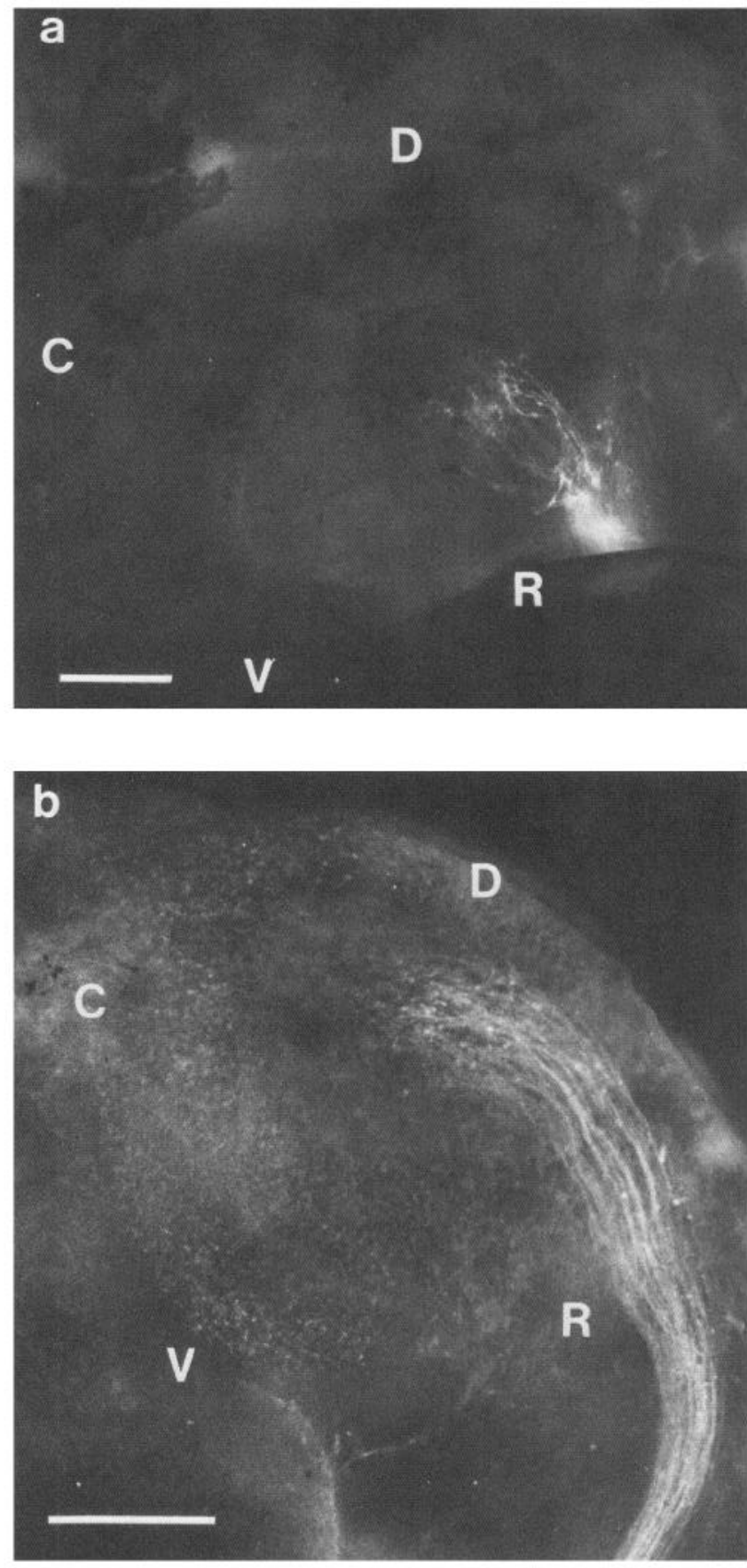

Figure 5. a, Insertion of small crystal of diI into ventrotemporal retina of TTX-injected embryo labels small group of axons. Their arbors are restricted to a cluster of small extent, localized to the retinotopically appropriate domain of the tectal neuropil. Scale bar, $40 \mu \mathrm{m}$. $b$, Retinotopically located cluster of terminal arbors of slightly larger extent than that shown in $a$ in tectum of noninjected embryo. $D$, dorsal; $R$, rostral; $V$, ventral; $C$, caudal. Scale bar, $50 \mu \mathrm{m}$.

selected to determine the rostrocaudal and mediolateral extent of the clusters, as well as the cluster area. One example of the TTX group is shown in Figure $5 a$, and 1 of the noninjected control groups is shown in Figure $5 b$. Each of these values was set in relation to the rostrocaudal and mediolateral extent and 

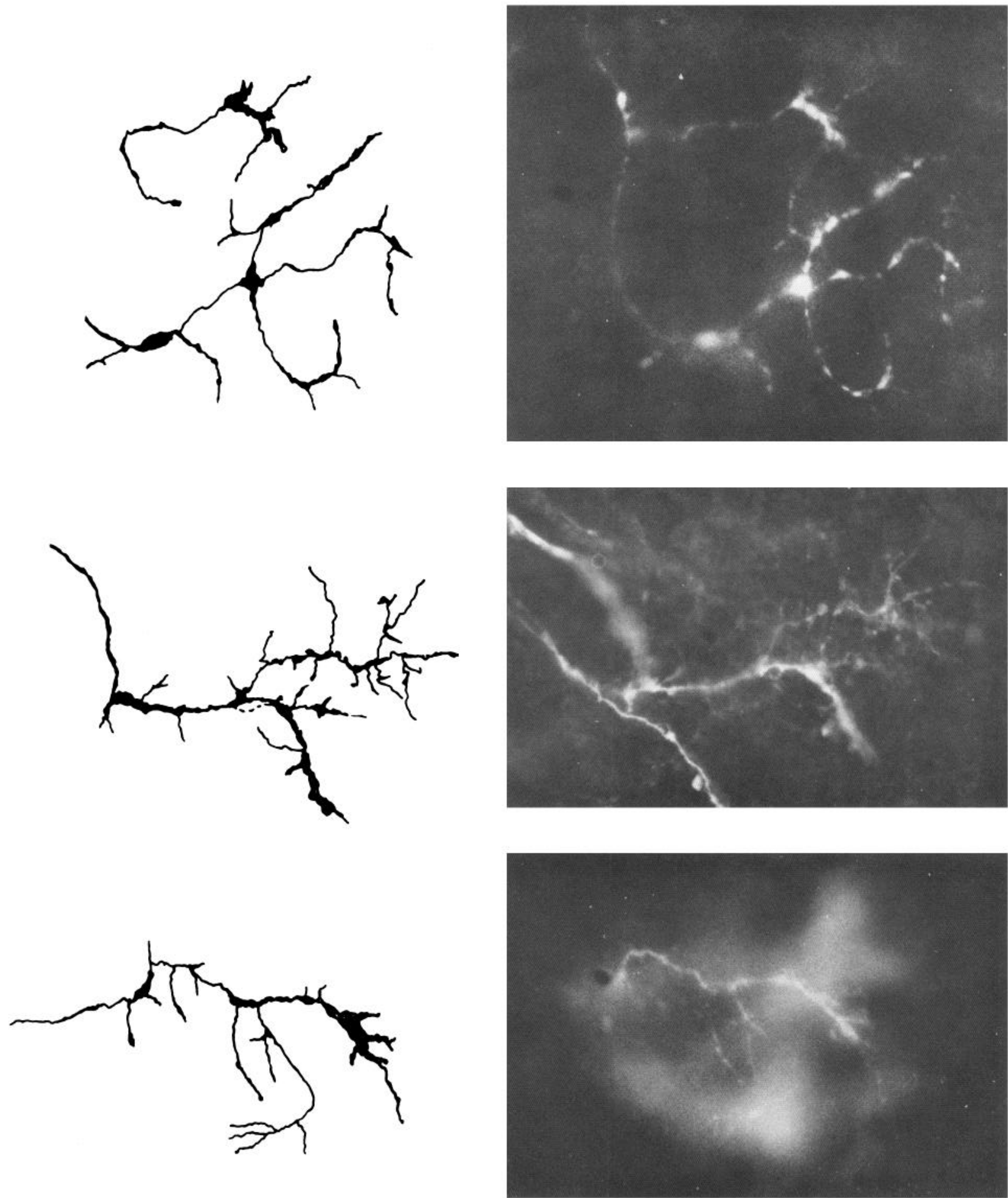

Figure 6. Photomicrographs (right) of 3 diI-labeled terminal arbors in tecta of TTX-injected embryos. Dil stains the arbors into their finest processes, which allowed them to be drawn (left) and their extent to be measured. Scale bar, $20 \mu \mathrm{m}$.

the area of neuropil of the very same tectum. In 8 tecta of TTXinjected fish and in 4 tecta of normal fish, the cluster extended over less than $10 \%$ of the tectal area. The 3 smallest clusters in the TTX group had dimensions of $25 \times 44,27 \times 44$, and 32 $\times 46 \mu \mathrm{m}$ in their rostrocaudal and mediolateral extent. The values of the axes of their tecta were $189 \times 143,189 \times 130$, and $210 \times 164 \mu \mathrm{m}$. These 3 clusters covered as little as 4.10 , 4.83 , and $4.27 \%$, respectively, of the surface area of their tecta. 
In the control group, the clusters measured $52 \times 22,40 \times 50$, and $50 \times 50 \mu \mathrm{m}$ in their rostrocaudal and mediolateral extent, and axes of the corresponding tecta were $185 \times 155,260 \times$ 120 , and $170 \times 160 \mu \mathrm{m}$ in length. The areas of these clusters occupied $4,6.4$, and $9.19 \%$, respectively, of the surface of their tecti.

These data indicate that the area occupied by the arbors of a group of activity-deprived axons from neighboring ganglion cells in the retina can be as small as that of arbors with normal activity patterns. These comparisons on cluster-size minima indicate that activity deprivation does not significantly disturb the retinotopic precision of axon targeting in the developing map (see Discussion).

\section{Terminal arbors}

The finding that axon arbors in TTX-injected embryos are confined to retinotopically well-defined domains suggests that blockade of activity had not caused an overall enlargement of the individual terminal arbors, a phenomenon that is characteristic for the TTX-silenced retinogeniculate axons in embryonic kittens (Srctavan ct al., 1988), as wcll as in the frog (Rch and Constantine-Paton, 1985). Measurements on a large number of individual terminal arbors confirmed that arbors of axons deprived of activity had, on average, not enlarged in size.

More than 100 tecta of TTX-injected embryos and embryos of the 2 control groups that had received diI-crystal applications in their retinae at 48-58 $\mathrm{hr}$ PF were screened. Arbors that were well labeled into their finest processes and lay isolated and distinct from neighboring arbors were drawn, and some were photographed (Fig. 6). Blockade of activity had no obvious effect on size of the arbors (Figs. 5, 7). To quantify arbor size, the most extreme tips of the branches were encircled by a smooth line and connected with the first branch or bifurcation point of the axon (see Materials and Methods and Stuermer, 1984, 1988c). Values of the long and short axes of the arbors in embryos at different age intervals between 70 and $100 \mathrm{hr}$ PF are given for the TTX-injected, Ringer-injected, and uninjected control groups in Figure 7. Consistent with our earlier findings (Stuermer, 1988c), small and large arbors were present in each of the 5 age intervals in all the TTX-injected, Ringer-injected, and uninjected control embryos. In all 3 groups, most arbors had axes smaller than 50 $\times 50 \mu \mathrm{m}$. A few arbors exceeded these values. In the TTXinjected, Ringer-injected, and uninjected groups, 7.8, 8.9, and $8.8 \%$ of the arbors, respectively, had long or short axes larger than $50 \mu \mathrm{m}$.

The mean arbor size in the TTX-injected group was $27 \times 18$ $\mu \mathrm{m}$, and that of the Ringer-injected and uninjected groups was $31 \times 22 \mu \mathrm{m}$. Thus, the mean arbor size in the TTX-group was actually smaller than that of the 2 control groups.

We considered whether arbors with the largest axes in the TTX group at 80-85 hr PF would indicate a trend towards a systematic increase in the arbors' long axes with increase in age in the TTX-treated animals. However, this did not appear to be the case. Arbors with such long axes also occurred in the Ringer-injected control group. In the TTX group, the long arbors were predominantly in 1 age class $(80-85 \mathrm{hr} \mathrm{PF})$, but were not found in embryos $10 \mathrm{hr}$ older. (All of these 80-85-hr embryos were from 1 batch, derived from different parents than the rest, and prepared 8 months later than all the remaining embryos.) Furthermore, the largest arbor of the TTX group (reaching almost $90 \mu \mathrm{m}$ in its long axis and $37 \mu \mathrm{m}$ in its short axis) actually a

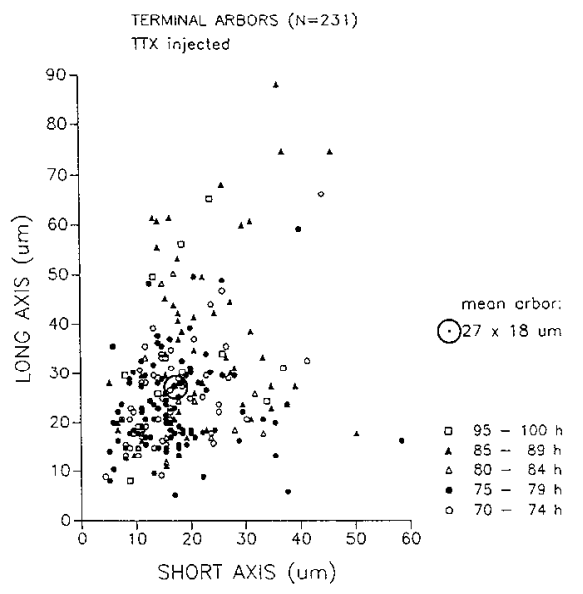

b

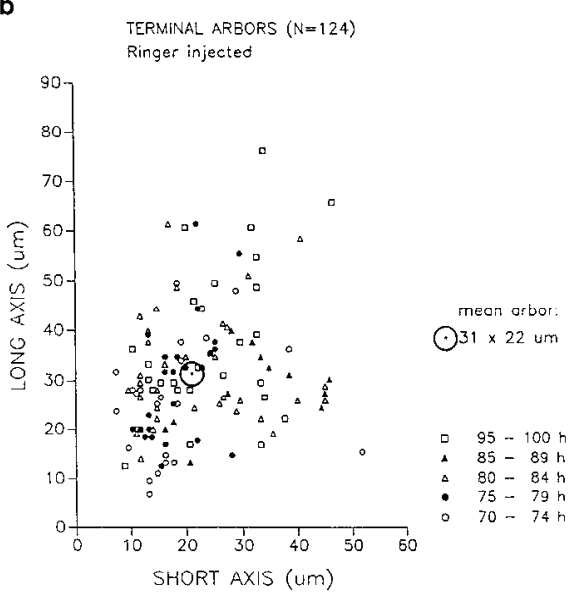

c

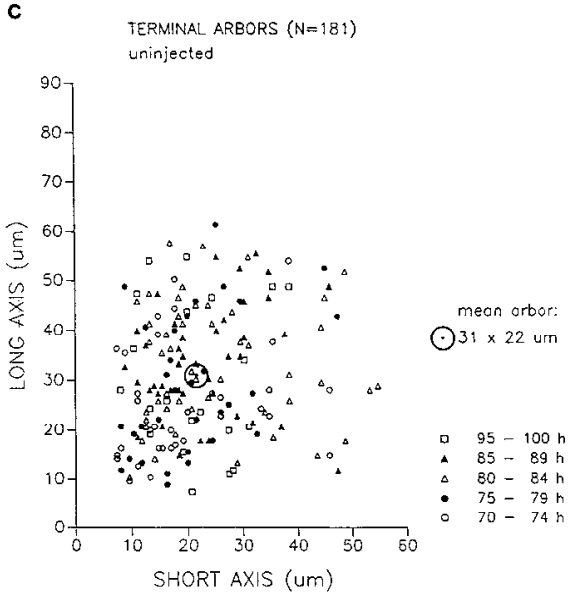

Figure 7. Plots of terminal-arbor long and short axes of embryos in 5 age intervals. $a$, TTX-injected embryos. $b$, Ringer-injected embryos. $c$, Uninjected embryos. The center of the circle indicates the mean of the long and short arbor axes.

derived from an axon that had bifurcated into 2 parallel running branches, which were bare of side branches over $40 \mu \mathrm{m}$ of their length, and which only had arborized extensively over their distal $50 \mu \mathrm{m}$. We had applied the same conventions to this arbor, that is, measuring the extent of the arbor from the first bifur- 
a

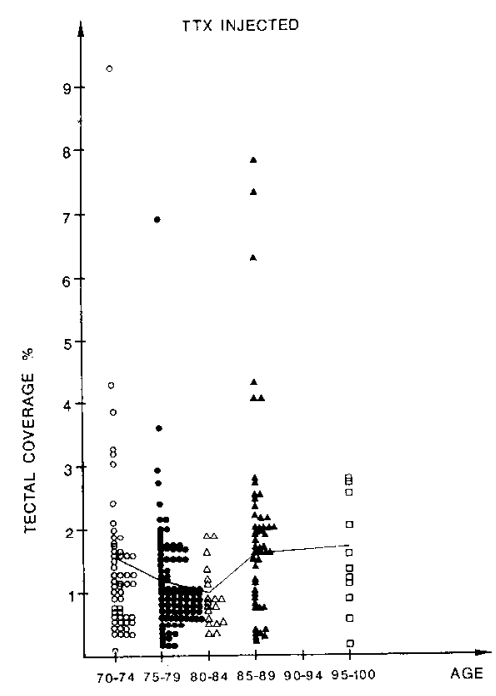

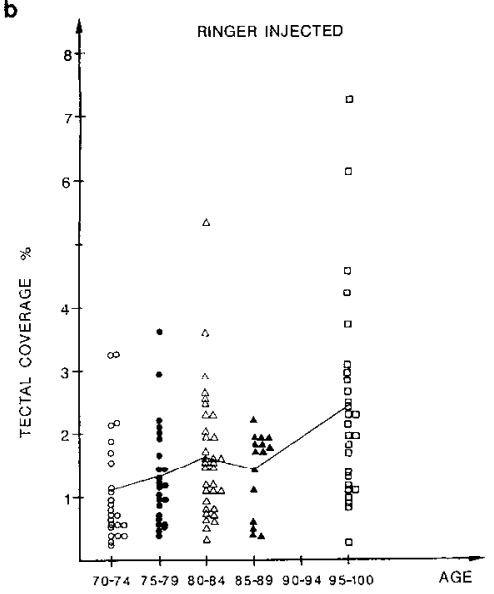

c

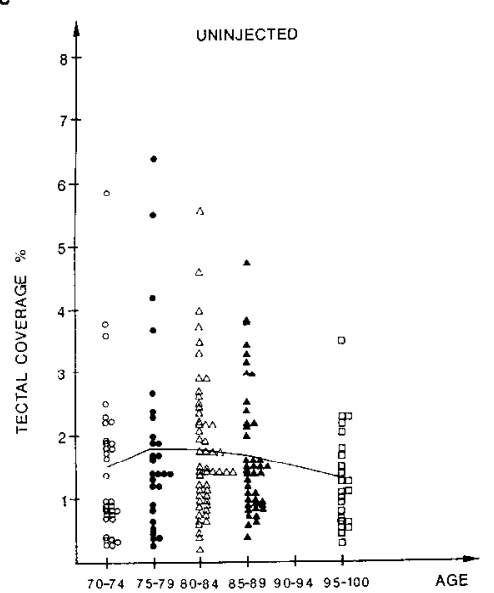

Figure 8. Plots of tectal coverage of embryos in 5 age intervals. The means of the coverage in each age interval is connected by a line. a, TTXinjected embryos. $b$, Ringer-injected embryos. $c$, Uninjected embryos.

cation point to the tips of the branches, though its actual arborizations were of much smaller extents.

\section{Tectal coverage}

To analyze whether the arbor size relative to the size of the tectal ncuropil would differ in TTX-paralyzed embryos compared to control embryos, the tectal coverage of arbors in 5 age groups was determined and compared (Fig. 8). As defined above and earlier (Stuermer, 1988c), the tectal coverage is the ratio between the area over which the branches of arbors extend and the area of the tectal neuropil. The areas of the tectal neuropil calculated as described in Materials and Methods are given in Figure 9, $a-c$. Consistent with our earlier measurements (Stuermer, 1988c) and as seen from these plots, the areas of the tectal neuropil varied considerably among individuals within each age group. This variation was found in the TTX group as well as in the 2 control groups. The means of the area values within each age group are connected by a line in Figure 9 . The mean of the values of all age groups was $30,824 \mu \mathrm{m}^{2}$ for the TTX-injected embryos, $36,619 \mu \mathrm{m}^{2}$ for the Ringer-injected embryos, and $34,109 \mu \mathrm{m}^{2}$ for the uninjected group. The neuropil area in the Ringer-injected group was larger than that of the uninjected group, but this difference was statistically insignificant. The tectal neuropil area in the TTX group was smaller than that of the 2 control groups, and this difference was statistically significant, but only at the 5\% level (KolmogoroffSmirnov test).

The tectal coverage, calculated from the average of the arbor areas in each age group and the average of the tectal arcas of the same age group, is plotted in Figure 8. The means of the tectal coverage varied hetween 1 and $2 \%$ in the TTX group, from 1.3 to $1.8 \%$ in the uninjected control group, and from 1.1 to $2.2 \%$ in the Ringer-injected control group. The means totals, averaged over all age groups, were $1.44 \%$ for the TTX-injected group, $1.62 \%$ for the Ringer-injected group, and $1.67 \%$ for the uninjected group. Thus, the tectal coverage of the terminal arbors in TTX-injected embryos appears smaller than that in the 2 control groups, but these differences were statistically insignificant even at the 5\% level (Kolmogoroff-Smirnov test).

\section{Discussion}

This study has used anatomical fiber-tracing methods to study the effect of TTX-induced neural-impulse blockade on the formation of the retinotectal projection in zebrafish embryos.

Activity-deprived axons from small groups of ganglion cells in the retina, labeled by diI and diO, arborize like active axons over small, well-localized, and retinotopically appropriate domains in the tectum. With respect to the location of the arbors and the areal extent over which arbors of a small group of neighboring ganglion cells cluster, targeting of TTX-blocked axons is as precise as of nondeprived axons. Consistent with this precision in terminal-arbor order is the finding that individual arbors of activity-blocked axons are not larger in size than those of active axons. Their tectal coverage, that is, the relative area of tectum occupied by the mean-sized arbors, is in size very similar to that of active axons. These findings lead to the conclusion that neural activity is not required for the establishment of a precisely organized retinotopic-terminal-arbor order in zebrafish embryos.

\section{Technical considerations}

The validity of these data rests on the notion that injections of the sodium-channel blocker TTX abolish the neural activity of the developing zebrafish retinal axons. The concentration and volume of the injected TTX solution was effective in inhibiting entirely the mobility of the embryos over more than $100 \mathrm{hr}$. Because motoneurons are known to have established functional contacts with their muscles in embryos younger than $30 \mathrm{hr}$ PF (Westerfield et al., 1986), immobility indicates that activity of motoneurons of the neuromuscular system or of muscles was effectively blocked by TTX. Furthermore, we confirmed, by electrophysiological recordings from embryos at 72-86 $\mathrm{hr} \mathrm{PF}$ having received TTX at $72 \mathrm{hr}$ PF, that TTX blocks activity in the CNS, including the firing of retinal axons in the tectum. Neither spontaneous nor light-induced activity was recordable from the tectum of embryos that had received TTX. Moreover, the spontaneous-activity pattern in the subtectal regions that is readily picked up by the electrodes in the Ringer-injected em- 
a

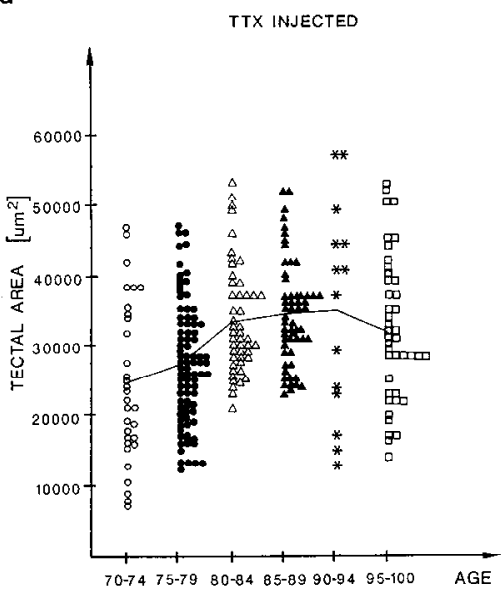

b

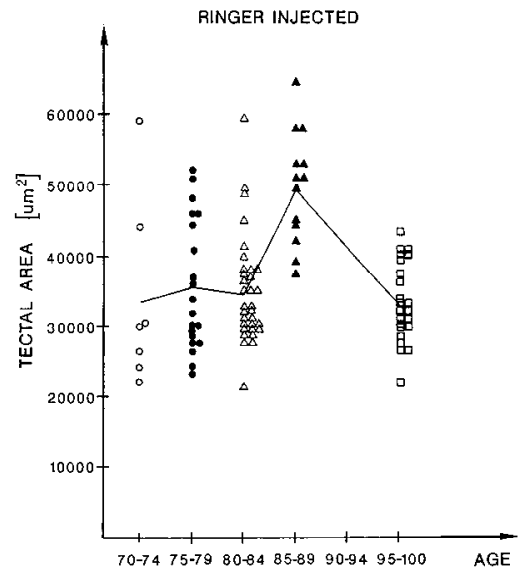

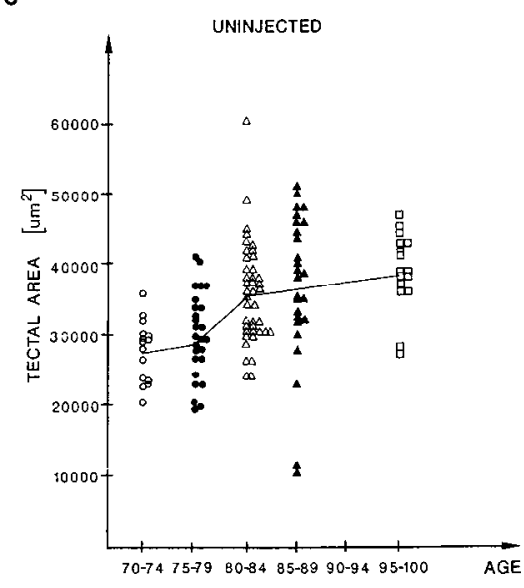

Figure 9. Plots of tectal neuropil area of embryos in 5-6 age intervals. $a$, TTX-injected embryos. $b$, Ringer injected embryos. $c$, Uninjected embryos. A line connects the means of the neuropil areas in each age interval.

bryos was also absent from TTX-injected fish. This also applied to embryos with TTX injections at 30-36 hr PF. They were paralyzed and had no spike activity in their tectum or in other parts of their midbrain even at $151 \mathrm{hr} \mathrm{PF}$ (the oldest embryos tested). However, recordings from tecta of embryos at 155 and $156 \mathrm{hr}$ PF that had partially recovered mobility and were purposely included revealed some light-evoked activity. Thus, it appears justifiable to conclude that block of motoneuron activity expressed by immobility of the embryos correlates with and is indicative of a block of sodium-channel-mediated impulse activity in the entire nervous system, including the retinal axons. This is in agreement with earlier work. Harris (1980) found that axolotl embryos parabiosed to TTX-producing newts were entirely immobilized much like our zebrafish. Moreover, Harris showed a strict correlation between blockade of motoneuron activity and blockade of impulse activity of the retinal axons. Thus, in his study, Harris used immobility of the embryos as an indicator for a general TTX-induced impulse blockade. We confirmed Harris's findings in our study. Consequently, embryos that had recovered mobility and twitched spontaneously or upon touch were discarded from our anatomical analysis.

Consistent with a number of earlier reports is the current observation that TTX prevents neither axonal growth into and arborization in the tectum, nor the overall development of the eye and the tectum (Harris, 1980, 1984). However, in some embryos, TTX may have lead to a delay in growth of the tectum, because some of the TTX-injected embryos exhibited smaller tectal neuropil areas and terminal-arbor extent than did embryos in the control groups.

In an earlier study (Stuermer, 1988c), the developing axons and their arbors were readily stained by intraocular applications of HRP. In the TTX-injected embryos in this study, HRP applications failed to label the axons, so TTX may have hindered axonal uptake or transport of HRP (Grafstein and Edwards, 1982). However, the lipophilic dyes diI and diO, which are incorporated into the membranes of the growing axons (Honig and Hume, 1986), proved to be very efficient for axonal staining. Why the intraaxonal uptake or transport of HRP is hindered in TTX-treated zebrafish embryos, but not in TTX-silenced regenerating axons of adult goldfish (Boss and Schmidt, 1984; Hartlieb and Stuermer, 1989), is not obvious. Because HRP would not label the TTX-blocked axons, we repeated the measurements on terminal arbors and tectal extent in normal embryos that were, as in the TTX-injected embryos, labeled with diI and diO, to obtain proper control values. This was necessary because the fixation and preparation of tectal whole-mounts and the tracing of the labeled axons differs, depending on whether HRP (Stuermer, 1988c) or the fluorescent dyes diI and diO were used. Furthermore, in this study, we analyzed many more developmental time intervals separately than in the earlier study. Given the methodological differences, the much larger number of embryos tested and the interindividual variability of tectum and arbor sizes, the values of the earlier HRP study (Stuermer, $1988 \mathrm{c}$ ) and the current diI/diO study are in good agreement.

Embryos at defined stages varied in size and in the size of their tecta. These size variations of age-related embryos were seen among TTX-and Ringer-injected, as well as in uninjected, embryos, and also among embryos of an earlier study (Stuermer, 1988c). Data for each of the age groups (x-axes in Figs. 7,9) were either from embryos of 1 clutch or collected over several months from embryos of different clutches. Even embryos of 1 clutch showed the same large variability of tectal size. It may perhaps be possible to eliminate this variability if zebrafish were inbred over several generations, but we did not have such embryos available.

By comparing the values of TTX-or Ringer-injected embryos that had been freed from their egg cases early in their development to the values of normal, uninjected embryos, it is clear that embryos develop outside their egg cases normally (Westerfield, 1989), and that the injection procedure is not harmful to their further development.

The broad range in the size of the arbors in the embryos compares to the occurrence of very large to small arbors in adult fish. Examples of a large and small arbor in adult zebrafish are shown in an earlier publication (Stuermer, 1988c). Their distribution is illustrated in a more quantitative approach in adult goldfish (Stuermer, 1984; Schmidt et al., 1988). These studies have shown that the number of very large arbors is small compared to the more numerous middle-sized and small arbors. It is likely, but has never been shown directly, that the differently sized arbors originate from morphologically and functionally different classes of ganglion cells (Stuermer, 1984). The co-oc- 
currence of a few large and many smaller arbors has also been demonstrated in goldfish embryos (Stuermer and Raymond, 1989). Therefore, the variation in arbor size seen in this study can be altributed, in part, to a natural and probably functionally significant diversity of ganglion cells and arbors in the tectum.

\section{Comparison with related findings}

The first report evaluating the influence of TTX-induced neuralimpulse blockade on the order of the retinotectal projection in lower vertebrates was Harris's study on axolotls (Harris, 1980, 1984). Using radioactive amino acids to label ganglion cell axons from defined retinal halves, Harris (1984) demonstrated that dorsal and ventral TTX-blocked axons project to their retinotopically appropriate halves of the $200-\mu \mathrm{m}$-wide tectum. Our present results on zebrafish embryos, which have a tectum as small as that of axolotls, agrees with Harris's findings (1980, 1984) and extends them. Dorsal and ventral axons in zebrafish, as well as temporal and nasal axons, terminate retinotopically despite neural-impulse blockade.

In Harris's study, available methods did not allow him to address the question of whether neural activity is required to achieve targeting of individual ganglion cell terminals more precise than projection to the appropriate hemitectum (Harris, 1984). Our study addressed this question in zebrafish embryos by labeling small groups of ganglion cells with the lipophilic dyes diI and $\mathrm{diO}$, which have proven to be appropriate to reveal the paths and termination patterns of small groups (Stuermer, 1988c) and even individual axons (Simon and O'Leary, 1989). Therefore, it was possible to show that small groups of TTX-blocked axons arborize over a portion of the tectal surface area that is as small as that occupied by axons with normal activity patterns and is much smaller than the $100-\mu \mathrm{m}$ hemitectum studied by Harris (1980, 1984). Furthermore, individual terminal arbors produced by activity-deprived axons are no larger than those of active axons.

The apparent lack of influcncc of TTX activity blockade on retinal-axon-arbor size in zebrafish contrasts with the emergence of abnormally large terminal arborizations by TTX-treated retinal axons in the kitten LGN (Sretavan et al., 1988). LGN arbors in the kitten are larger initially and become restricted to their eye-specific layer of the LGN by a selective elimination of those parts of the arbors that reside over the inappropriate LGN layer (Sretavan and Shatz, 1986). TTX not only blocks this process of pruning, but also leads to sprouting of branches and to an increase in total arbor extent. Because the arbors are large not only in their vertical but also in their lateral extent, the retinotopicity of the retinogeniculate projection deteriorates (in addition to the failure of laminar segregation; Sretavan et al., 1988). Blockade of neural activity also leads to production of additional branches, as has been found in the frog tectum, which was doubly innervated because of the early implantation of a third eye. TTX caused a desegregation of the eye-specific stripes, and in this desegregated projection, the individual arbors were larger than in the "striped" tectum (Reh and Constantine-Paton, 1985).

The present anatomical study has demonstrated that neither the size of the terminal arbors and their tectal coverage nor the retinotopic termination of small groups of axons change with TTX-induced neural-impulse blockade in zebrafish embryos. Therefore, mechanisms other than neural activity must be responsible for the establishment of a precisely organized retinotopic map. In the regenerating retinotectal system in adult fish and in axolotl embryos, it has been shown that preordering of axons along their path from the eye to the tectum is also dispensible for the formation of a retinotopic terminal order in the tectum (Harris, 1984; Stuermer and Easter, 1984a; Stuermer, 1988a,b); thus, axon-target recognition by spatial markers appears to play the predominant role in the establishment of a well-organized retinotopic map in lower vertebrates (Gierer, 1987).

We should note, however, that neither our nor earlier investigations have ruled out the possibility that electrical activity mediated by other ion channels may be used for the interaction of the axons with one another and with their target.

\section{Fine tuning of projections}

While anatomical methods are suited to determine the retinotopic precision of terminal-arbor order, they are not appropriate to evaluate the development of physiological properties and their dependence on neural-spike activity. There are steps in the fine tuning of a projection that are revealed with electrophysiological recordings. One example is the formation of the retinotopic map by regenerating goldfish retinal axons that evolves differently from the embryonic map (Stuermer and Easter, 1984a; Meyer et al., 1985; Stuermer, 1988a,b). Anatomical methods have shown that regenerating axons that travel in abnormal routes and branch initially widely (Stuermer, 1988b,c; Schmidt et al., 1989) are able to seek out their targets and form focused arbors over retinotopically appropriate and small domains in the tectum despite TTX-induced impulse blockade (Hartlieb and Stuermer, 1989). Electrophysiological recordings, however, showed that the MURFs (multiunit receptive fields) are 2.5 times larger in tecta innervated by TTX-blocked axons (Schmidt and Edwards, 1983). This was so at the time that tecta innervated by active axons exhibited MURFs of normal sizes (Schmidt and Edwards, 1983). Because MURF sizes in regenerated projections are large initially, then shrink, this study suggests that TTX-induced impulse blockade prevents MURF-size shrinkage (Schmidt and Edwards, 1983) or causes a delay of this process (Hartlieb and Stuermer, 1989). The anatomical fiber-tracing technique would not detect this imprecision, which probably is caused by slight arbor displacements (Schmidt and Edwards, 1983; Schmidt, 1985), unless the area occupied by a small group of axon arbors of neighboring ganglion cells would become considerably larger under activity deprivation. But this is not the case (Hartlieb and Stuermer, 1989).

Enlarged MURFs may be a result of an imprecision in arbor placement such that arbors that normally overlap to a certain extent would, under TTX, be out of register (Schmidt, 1985). MURF sizes of retinal axons in embryonic zebrafish tecta have not been determined. Therefore, it remains open whether activity is required for the "fine tuning" of the projection, defined electrophysiologically. A related example of fine tuning of a projection in mammals that is activity dependent is the segregation of inputs from functionally distinct classes of retinal ganglion cells onto LGN neurons (Dubin et al., 1986). TTX blocks this segregation (Dubin et al., 1986). Whether TTX has similar effects in zebrafish has not been studied. Perhaps the best-known example of activity-dependent effects on visual projection is the sorting of projections from different eyes in mammals and coldblooded vertebrates. Activity deprivation prevents the formation of eye-specific laminae in the LGN (Sretavan et al., 1988), of ocular-dominance columns in the cortex (Stryker and Harris, 1986), and of eye-specific domains in doubly innervated tecta 
of frogs and fish (Reh and Constantine-Paton, 1985; Boss and Schmidt, 1984).

\section{Map refinement during growth towards adulthood}

In amphibian and fish visual systems, a unique developmental process occurs as the retinae and tecta enlarge and add new neurons (Raymond and Easter, 1983). In zebrafish (Stuermer, $1988 \mathrm{c}$ ), as in Xenopus (Sakaguchi and Murphey, 1985), the arbors are initially small, but increase in size as the animal grows. The tectum enlarges even more, so that the tectal coverage of the arbors decreases despite increase in arbor size (Sakaguchi and Murphey, 1985; Stuermer, 1988c). Maintenance of retinotopia during this process is guaranteed by shifting of the arbors (Constantine-Paton et al., 1983; Easter and Stuermer, 1984; Stuermer, 1984, 1988a; Stuermer and Easter, 1984b).

Whether these events are dependent on sodium-channel-mediated activity has not been investigated. A recent report on effects of aminophosphonovaline-induced NMDA-receptor blockade in frogs, however, suggests that perhaps shifting may be an activity-independent process (Cline and Constantine-Paton, 1989).

\section{Differences in the formation of precisely ordered projection patterns in mammals and zebrafish}

A few studies have been cited here that exemplify the differences in the formation and maintenance of retinal-axon-termination patterns in lower vertebrates and mammals. As more refined techniques are applied, further differences have been demonstrated more clearly. One such example is the development of the retinocollicular projection in mammals, the homologue of the lower-vertebrate retinotectal projection. In rats, for instance, the retinocollicular axons initially arborize widely over their target field, and only gradually will arbors become pruned and focused or eliminated by cell death (Simon and O'Leary, 1989). Improvement of retinotopia by cell death occurs to a considerable degree despite TTX-induced neural-activity blockade in rats (O'Leary et al., 1986). Whether morphological changes of arbors, such as pruning, are activity dependent in the rat colliculus has not yet been reported.

In contrast to the mammalian retinocollicular arbors (Schneider et al., 1981; Simon and O'Leary, 1989), fish retinotectal arbors are small and precisely positioned from the start (Stuermer, 1988c; Stuermer and Raymond, 1989). There is no arbor pruning in normal development, nor has cell death been found. Instead, as more ganglion cells are born, more axons arrive in the tectum (Raymond and Easter, 1983) and arbors shift (Easter and Stuermer, 1984). These differences between mammalian and cold-blooded vertebrates give rise to the speculation that retinal ganglion cells and their axons in these species differ intrinsically in their developmental programs, and may also differ in the amount of influence that is given to activity-driven axontarget interactions in shaping a terminal pattern.

This speculation is further supported. The phenomenon of precise wiring is in zebrafish not confined to the retinotectal system. It also applies to the primary motoneurons that innervate in a stereotypic and specific pattern their axial musculature (Westerfield et al., 1986). Evidence from mammals and other vertebrates suggest a role for activity and trophic interactions in shaping the final pattern of neuromuscular projections (Thompson et al., 1979; Easter et al., 1985). This is apparently not so in zebrafish. Embryos that had been paralyzed by local anesthetics throughout the period of axonal outgrowth and tar- geting, as well as embryos bearing mutations that abolish muscle contractions (Felsenfeld and Westerfield, 1986) or functional acetylcholine receptors (Westerfield et al., 1987), all establish normal innervation patterns. This finding gave rise to the proposal that some forms of activity-mediated interactions are not required for proper establishment of the initial pattern of projections in zebrafish (Kimmel and Westerfield, 1990).

\section{References}

Boss WC, Schmidt JT (1984) Activity and formation of ocular dominance patches in dually innervated tectum of goldfish. J Neurosci 4: 2891-2905.

Cline HT, Constantine-Paton M (1989) NMDA receptor antagonists disrupt the retinotectal topographic map. Neuron 3:413-426.

Constantine-Paton M, Pitts EC, Reh T (1983) The organization of the optic pathway and its relationship to termination in the retinotectal system of Rana pipiens. J Comp Neurol 218:298-313.

Dowben RM, Rose JE (1953) A metal-filled microelectrode. Science $118: 22-24$

Dubin MW, Stark LA, Archer SM (1986) A role for action-potential activity in the development of neuronal connections in the kitten retinogeniculate pathway. J Neurosci 6:1021-1036.

Easter SS, Stuermer CAO (1984) The evaluation of the hypothesis of shifting terminals in goldfish optic tectum. J. Neurosci 4:1053-1063.

Easter SS, Purves D, Rakic P, Spitzer NC (1985) The changing view of neural specificity. Science 230:507-511.

Felsenfeld A, Westerfield M (1986) Normal pathfinding and synapse formation by motoneurons in a non-motile mutant zebrafish embryo. Soc Neurosci Abstr 12:547.

Gierer A (1987) Directional cues for growing axons forming the retinotectal projection. Development 101:479-489.

Godement P, Vanselow J, Thanos S, Bonhoeffer F (1987) A study in developing visual systems with a new method of staining neurones and their processes in fixed tissue. Development 101:697-713.

Grafstein B, Edwards DL (1982) Effect of physiological activity in goldfish optic axons on axonal transport of protein and nucleosides. In: Axoplasmic transport in physiology and pathology (Weiss DG, Gorio A, eds), pp 21-26. Berlin: Springer.

Harris W (1980) The effects of eliminating impulse activity on the development of the retinotectal projection in salamanders. J Comp Neurol 194:303-317.

Harris WA (1984) Axonal pathfinding in the absence of normal pathways and impulse activity. J Neurosci 4:1153-1162.

Hartlieb E, Stuermer CAO (1989) Pathfinding and target selection of goldfish retinal axons regenerating under TTX-induced impulse blockade. J Comp Neurol 284:148-168.

Honig MG, Hume RJ (1986) Fluorescent carbocyanine dyes allow living neurons of identified origin to be studied in long-term cultures. J Cell Biol 103:171-187.

Kimmel CK, Westerfield M (1990) Primary neurons of the zebrafish. In: Signal and sense: local and global order in perceptual maps. (Edelmann GM, Gall WE, eds). New York: Wiley.

Meyer RL, Sakurai K, Schauwecker E (1985) Topography of regenerating optic fibers in goldfish traced with local wheat germ injections into retina: evidence for discontinuous microtopography in the retinotectal projection. J Comp Neurol 239:27-43.

O'Leary DDM, Fawcett JW, Cowan M (1986) Topographic targeting errors in the retino collicular projection and their elimination by selective ganglion cell death. J Neurosci 6:3692-3705.

Purves D, Lichtman JW (1985) Principles of neural development. Sunderland: Sinauer.

Raymond P, Easter SS (1983) Postembryonic growth of the optic tectum in goldfish. $J$ Neurosci 3:1077-1091.

Reh TA, Constantine-Paton M (1985) Eye-specific segregation requires neural activity in three eyed Rana pipiens. J Neurosci 5:11321143.

Sakaguchi DS, Murphey RK (1985) Map formation in the developing Xenopus retinotectal system: an examination of ganglion cell terminal arborizations. J Neurosci 5:3228-3245.

Schmidt JT (1985) Formation of retinotopic connections: selective stabilization by an activity-dependent mechanism. Cell Mol Neurobiol 5:65-84. 
Schmidt JT, Edwards DL (1983) Activity sharpens the map during the regeneration of the retinotectal projection in goldfish. Brain Res 269:29-39.

Schmidt JT, Turcotte JC, Buzzard M, Tieman DG (1988) Staining of regenerated optic arbors in goldfish tectum: progressive changes in immature arbors and a comparison of mature regenerated arbors with normal arbors. J Comp Neurol 269:15-27.

Schmidt JT, Turcotte JC, Buzzard M, Tieman DG (1989) Staining of regenerated optic arbors in goldfish tectum: progressive changes in immature arbors and a comparison of mature regenerated arbors with normal arbors. J Comp Neurol 269:565-591.

Schneider GE, Rava L, Sachs GM, Jhaveri S (1981) Widespread branching of retinotectal axons: transient in normal development and anomalous in adults with neonatal lesions. Soc Neurosci Abstr 7:732.

Simon DK, O'Leary DDM (1989) Lack of topographic precision in the targeting of mammalian retinal axons. Soc Ncurosci Abstr 16: 495.

Sretavan DW, Shatz CJ (1986) Prenatal development of retinal ganglion cell axons: segregation into eye-specific layers within the cat's lateral geniculate nucleus. J Neurosci 6:234-251.

Sretavan DW, Shatz CJ, Stryker MP (1988) Modification of retinal ganglion cell axon morphology by prenatal infusion of tetrodotoxin. Nature 336:468-471.

Stryker MP, Harris WA (1986) Binocular impulse blockade prevents the formation of ocular dominance columns in cat visual cortex. $J$ Neurosci 6:2117-2143.

Stuermer CAO (1984) Rules for retinotectal terminal arborizations in the goldfish optic tectum. A wholemount study. J Comp Neurol 229: 214-232.

Stuermer CAO (1988a) The trajectories of regenerating retinal axons in the goldfish. I. A comparison of normal and regenerated axons at late regeneration stages. J Comp Neurol 267:55-68.
Stuermer CAO (1988b) The trajectories of regenerating retinal axons in the goldfish. II. Exploratory branches and growth cones on axons at early regeneration stages. J Comp Neurol 267:69-91.

Stuermer CAO (1988c) Retinotopic organization of the developing retinotectal projection in the zebrafish embryo. J Neurosci 8:45134530.

Stuermer CAO (1988d) Development of the retinotectal projection in zebrafish embryos under TTX-induced blockade of neural activity Soc Neurosci Abstr 14:178.

Stuermer CAO, Easter SS (1984a) A comparison of the normal and regenerated retinotectal pathways of goldfish. J Comp Neurol 223 $57-76$.

Stuermer CAO, Easter SS (1984b) Rules of order in the retinotectal fascicles of goldfish. J Neurosci 4:1045-1051.

Stuermer CAO, Raymond PA (1989) Developing retinotectal projection in larval goldfish. J Comp Neurol 281:630-640.

Thompson W, Kuffler DP, Jansen JKS (1979) The effect of prolonged, reversible block of nerve impulses on the elimination of polyneuronal innervation of new-born rat skeletal muscle fibers. Neuroscience 4 : 271-281.

Udin SB, Fawcett JW (1988) Formation of topographic maps. Annu Rev Neurosci 11:289-327.

Westerfield M (1989) The zebrafish book. Eugene, OR: University of Oregon.

Westerfield M, McMurray JV, Eisen JS (1986) Identified motoneurons and their innervation of axial muscles in the zebrafish. J Neurosci 6 : 2267-2277.

Westerfield M, Kimmel CB, Walker C (1987) Normal pathfinding by pioneer motor growth cones in mutant zebrafish lacking functional acetylcholine receptors. Soc Neurosci Abstr 13:5. 